\title{
Payment mechanisms for integrated teams in construction
}

Ibrahim Motawa and Ammar Kaka

School of the Built Environment, Heriot Watt University, UK

\section{ABSTRACT}

The overwhelming consensus for process and team integration has emerged as an enabler to manage construction projects. The performance of integrated teams is highly affected by the adopted payment mechanism. However, the payment mechanisms available for a project may need the team to compromise in order to agree on a fair mechanism for as many members as possible. This paper introduces a methodology to simulate the profiles of alternative payment mechanisms. The methodology aims to help project teams define the most appropriate mechanism for each member. The proposed methodology is therefore novel and superior to existing cash flow models where the focus has been limited to main contractors only. To promote its use as a performance enabling mechanism, the methodology utilizes "the project process map", "the stakeholders \& supply chain", "the pricing method" and "the payment mechanism". This will act as an aid to design or "fine-tune" payment mechanisms to individual projects characteristics considering payment for off-site materials and components, which always concerns project fabricators and supply chain.

Keywords: Payment mechanisms, Pricing methods, Construction process.

\section{INTRODUCTION}

The role of payment mechanisms in construction contracts inspired many researchers to categorise the types of contracts by the types of payment mechanisms, for example: Williams (1992), O'Reilly's (1993), Potts (1995) and Smith (2002). Contracts that specify 'lump-sum' and wholly 'cost-reimbursable' payment are acknowledged by IChemE (2003) to be the extremes of a wide range of forms of contracts that allocate risks and responsibilities between the contracting parties in different ways. A variety of forms of payment was listed by IChemE (2002) as:

- reimbursable cost-plus a percentage-fee;

- reimbursable cost-plus a fixed-fee;
- target cost (shared over-run and/or underrun);

- unit-rate (including re-measure);

- guaranteed maximum price;

- lump-sum services and materials with reimbursable construction;

- lump-sum (i.e. wholly lump-sum).

Nonetheless, other payment methods such as the open-book accounting, stage payments, incentive contracting, direct payment, trust accounts/funds, mobilisation advance payment and the mechanic's lien have been shown to be versatile and useful in different project situations. Such alternatives may allow for better and active participation of the project members so as to ensure that the project objectives are well understood and delivered. For example, with the use of a costreimbursable method, the contractor is involved at a very early stage in the project and contributes by his/her own expertise in buildability, costing, material ordering, and programming, Masterman (2002). A stage payment method reduces administration time and cost to prepare interim payments and allows the responsible project personnel to be engaged in more productive project activities, Potts (1988) and Cheetham et al. (1995). Incentive payment method is often employed with disincentives so as to instil efficient contract arrangement and to reward the successful contractors who are fully motivated so as to achieve the client objectives with high performance standards, Arditi \& Yasamis (1998) and Bubshait (2003). A direct payment method allows subcontractors and suppliers to be paid promptly and in full which should result in lower prices, better performance and faster completion, Clough \& Sears (1994). Trust accounts and mechanics liens could be set up to protect and compensate the project participants who have invested in the project against a client or main contractor going out of business and/or not fulfilling their payment commitment, Clough \& Sears (1994) and Latham (1994). Projects' contractors and subcontractors could also be paid in advance to assist them in starting the project and maintaining a healthy cash-flow, Abeysekera (2002). 
Each payment mechanism could be appropriate for certain conditions of a project and client circumstance. For example, the traditional methods of the lump-sum and unitprice are useful when there is adequate information to produce a complete design, thereby, allowing proper contractor competition, low tender prices, easy assessment of interim valuations and variations for payment, and higher level of certainty that quality and functionality standards will be attained, Smith (2002), IChemE (2003) and Masterman (2002).

\section{RESEARCH AIM}

This research was motivated by three observations. The first observation came out of the results of the above literature review that have shown that each payment mechanism has its advantages and disadvantages. Choosing the appropriate pricing and payment method, from the available ones, has a positive effect on the management and delivery of projects. Meanwhile, the overwhelming consensus for process and team integration in construction projects emerges the need for considering the potential payment method in cash flow modelling for integrated teams. The agreed payment mechanism motivates the team to perform efficiently. As the team integration creates different direct/indirect managerial and contractual links throughout the supply chain, these links are undoubtedly influencing payment and cash flow mechanisms. Payment mechanisms therefore, have to be designed in response to the sensitivity of these links to the team performance and satisfaction. The degree of involvement of the team members in deciding on the appropriate payment method affects the behavioural aspects of project teams. This could be improved if the negotiation to reach the most suitable payment method efficiently allows all options to be considered. However, the current practice starts by the agreement between the client and the main contractors. The main contractors may then negotiate, based on this agreement, with the other team members. This obviously limits the margin of negotiation and put unfair strain on the other parties, which in turn affects their satisfactions.

Therefore, this research aims to address the need for Performance-Based contracts, which are gaining momentum in construction contracts. The concept of these contracts is to align targets and clients' satisfaction with payments, encourage collaborative working, ensure that risks are allocated accordingly, remove the adversarial approach by reimbursing the contractor fully and guaranteeing his profit, and provide a source of motivation that make project delivery much more effective. In this respect, and by enhancing the cash flow profile of the project team members, this research will help improving the team performance and satisfaction.

The second observation was based on the fact that many contractors have used different ways to enhance projects cash flow. Some ways have been found in more efficient management processes and information systems which allow contractors to minimise the outstanding balances owed by clients. Some other ways have been found through pricing policies (e.g. unbalancing and front-end loading) or unfair procedures such as overmeasurement and delaying payments to subcontractors and suppliers. However, enhancing cash flow through analysing alternative payment mechanisms from a supply chain perspective has not been fully addressed. Taking a wider supply chain perspective, the conventional payment mechanism places a considerable and unfair strain on particular parties and thus on the overall spirit of team working, partnering and supply chain management, Egan (1998). Therefore, this research is also aiming to promote and facilitate the use of appropriate payment mechanisms considering the flow of payments throughout the supply chain.

The third observation was based on the fact that the problem of the payment for off-site materials and components is among the causes of cash flow failure. Contractors are usually paid for the work done in addition to any materials already on site. Off-site materials and/or work, which become substantial in the modern prefabricated and pre-assembled components, are not paid until provided on site. This mechanism of payment affects the contractors' cash flow negatively and consequently the supply chain. Therefore, this research is also aiming to enable the project team to effectively manage the payment for off-site work/materials.

In this paper, a methodology to simulate different payment mechanisms for integrated teams in construction projects is proposed. The methodology defines all construction stages and when each project member will be involved. The available pricing and payment mechanisms will then be tested in order to define the most appropriate ones for each member. This methodology is based on the 
system developed by the authors, Motawa and Kaka (2006), to further simulate payments for the supply chain members and payment for off-site work/materials.

\section{METHODOLOGY TO SELECT PAYMENT MECHANISM}

The adopted methodology to select the appropriate payment mechanism, as shown in Figure 1, considers first the stages of the Project Process Map (PPM). PPM defines the products, services, management, design, engineering, and prefab \& assembly needed for a project. Having a process map enables the project team to agree on a common framework for managing and controlling a project in order to meet the client's business needs. This will result in far fewer problems and minimizing effort and duplication. The project team can use their experience to continually refine and improve such process. A typical process map represents a logical sequence of action that will not prejudice progress. Most of the detailed actions that must be taken under the common framework of a process map are considered to be matters of normal good practice of a particular profession, and must be planned and carried out in the light of each project conditions. Many process maps have been developed to represent construction projects. Among the maps known to practitioners in the UK, there are the architect's plan of work (RIBA (2001)) and the Process Protocol (Kagioglou et al (1998)), which are adopted for this research. Having such a process map will help simulating the payment requirements within design and construction stages in order to analyse the effect of using alternative payment mechanisms on the cash flow of the stakeholders and supply chain members.

The "stakeholders \& supply chain" defines the products and the services they will be providing, and the contractual and cash flow arrangements between them. The concept of supply chain management is emerging as a significant performance enabler for the construction industry. Partnering arrangements are enabling stakeholders to take more strategic and long term approaches to the production, running and maintenance of buildings. Contractual organisations are becoming more complex to define and manage the managerial and contractual links throughout the supply chain. These links are undoubtedly influencing payment and cash flow mechanisms. The involvement of the supply chain members from the early stages of projects needs suitable contractual agreements and procurement methods to regulate the relationships between these members. This proposed methodology explores the cash flow between the partners to a contract, as procurement decisions have been malleable to project situations then payment mechanisms can similarly be made bespoke to the benefit of project performance and client satisfaction.

The process maps give details to all construction processes that cover a project from the conceptual stage to the operational and maintenance stage. This will help identifying who is paying whom from the defined stakeholders and supply chain and when payments are due. A full project program will then be generated using a project management tool.

The Pricing and Payment methods, as shown in Figure 1, refer to the way in which each product or service is to be priced and paid. All available options can be considered, for example: payment time lags, retention arrangement, payments for off-site materials, etc.

At this stage, the adopted methodology covers the features of the payment mechanism for fixed price contracts, cost reimbursement contracts, and incentive contracts. Different payment conditions within these payment mechanisms are considered, such as: interim payment (e.g. monthly payment), stage payment (when certain milestones are defined for payment), and mobilized advanced payment.

The IT system developed to automate the adopted methodology will generate the cash flow for each project member, as defined by Equation 1 and shown in Figure 2, with all data required to test different payment mechanisms for each individual member.

Cashflow $_{(i)}=$

$\int_{0}^{D}\left(f\left(C, T_{c}\right)-f\left(P, T_{p}\right)\right)_{i}^{l} \ldots \ldots \ldots . .$. Eqn. (1)

Where $C$ is the total cost at the time $T_{c}$,

$P$ is the total payment at the time $T_{p}$,

$D$ is the total project duration,

$i$ represents the assigned stakeholder or supply chain member, and

$I$ represents the level of the $i$ member on the chain $(I=1$ or 2$)$ 
Figure 1. Methodology to select payment mechanisms

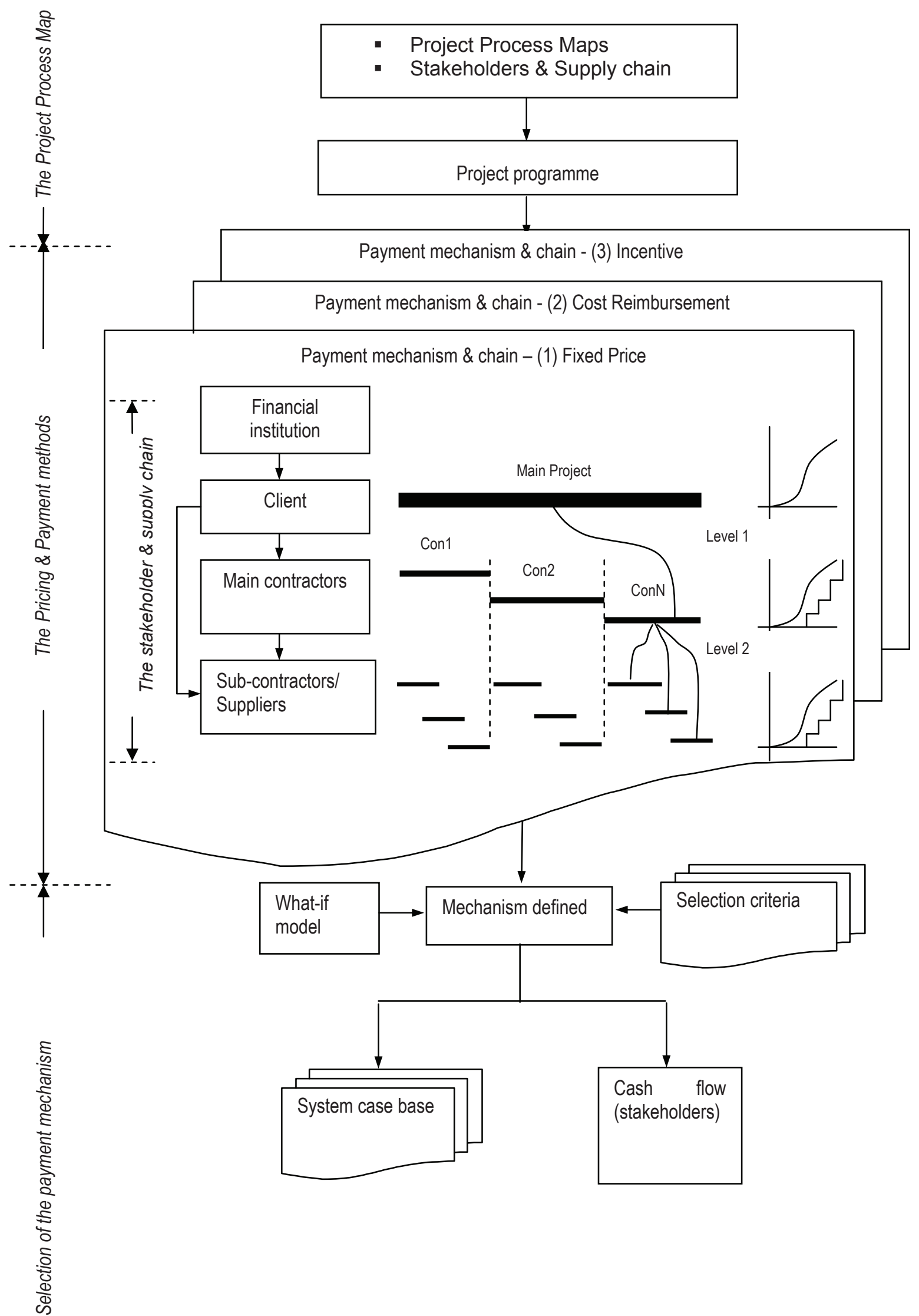




\section{PAYMENT FOR OFF-SITE MATERIALS}

Payment for off-site materials and components has always been a concern for project fabricators. The proposed methodology considers the costs of off-site activities (e.g. materials and prefabricated or pre-assembled units) as a percentage to the total costs of individual activities, as defined in Equation 2.

$\int_{0}^{D} f\left(C, T_{c}\right)_{\text {off-site }}=Y^{*} \int_{0}^{D} f\left(C, T_{c}\right) \quad$ Eqn.(2)

Where $Y$ is the percentage assumed for the off-site activities

The system allows breaking down the costs of off-site activities with corresponding time lags for installation on-site, which allows for activities done before the actual start of construction to be considered as defined by Equations 3:

$$
\int_{-T 1}^{D-T 1} f_{1}\left(C, T_{c}\right)_{o f f-s i t e}=X_{1} * \int_{0}^{D} f\left(C, T_{c}\right)_{o f f-\text { site }} \text { Eqn.(3) }
$$

Where $X_{1}$ represents the percentages of the off-site costs to the total off-site costs, corresponding to a time lag $T_{1} \cdot T_{1}$ may represent off-site units ordered before the actual start of construction. Other percentages and time lags $\left(X_{j}\right.$ and $\left.T_{j}\right)$ can be defined to represent the costs of all off-site activities. The total costs of off-site activities can then be determined by Equations 4:

$\int_{N}^{0} f_{x}\left(C, T_{c}\right)_{\text {off-site }}=\int_{-T 1}^{D-T 1} f_{1}\left(C, T_{c}\right)_{\text {off-site }}+\int_{-T 2}^{D-T 2} f_{2}\left(C, T_{c}\right)_{\text {off-site }}+\ldots \ldots . .$. Eqn. $(4)$

Where $\mathrm{N}$ is the earliest start time of off-site activities before construction start.

The system allows for the off-site activities to be considered for any chosen payment mechanism in any of the following ways:

1. Not to be considered until provided on site and when construction starts.

2. To be fully considered before provided on site and before construction starts.

3. To be partially considered before provided on site, then fully considered once construction starts.

The payment profile will be modified to accommodate these assumptions, as shown in Equation 5,
Payment-profile $_{(i)}=$

$$
Z * \int_{N}^{0} f\left(P, T_{p}\right)_{i}^{l}+\int_{0}^{D} f\left(P, T_{p}\right)_{i}^{l} \text { Eqn.(5) }
$$

$Z$ represents the percentage of the payment for the off-site materials/components:

$Z=0$, means the off-site materials are not considered until provided on site

$Z=1$, means the off-site materials are fully considered before provided on site

$0<Z<1$, means the off-site materials are partially considered

The cash flow for each project member can then be modified, as defined by Equation 6 .

Cash flow $(i)=$
$\int_{N}^{0}\left(f_{x}\left(C, T_{c}\right)_{o f f-s i t e}-Z * f\left(P, T_{p}\right)\right)_{i}^{t}+\left(100-Y^{*} \int_{0}^{D}\left(f\left(C, T_{c}\right)-f\left(P, T_{p}\right)\right)_{i}^{l}\right.$
Eqn.(6)

The IT system developed to automate the adopted methodology is based on a large database. The database is used to retrieve the stages of project process maps. The database is integrated with Microsoft Project database to enable producing the project programme relevant to each member of the stakeholders and supply chain. It is also retrieving the necessary data to calculate the effect of different payment mechanisms on project cash flow. Other planning and control data, as categorised in Figure 3 and 4, may also be entered, if needed. The system produces numerical and graphical outputs that represent the effect of different payment mechanisms. The system output describes the cash flow profile for any combination amongst the available methods, for example: a lump-sum with monthly payment or cost reimbursement with stage payment.

\section{SYSTEM APPLICATION}

An example has been developed to illustrate the system use, as shown in Table 1. The example shows the typical activities of a building project with components constructed off-site and requested before construction starts. Five main companies, given the names $A, B, C, D$, and $E$, are working as the project contractor and paid directly by the client. Table 1 also shows a number of subcontractors; A1, C1, E1, E2, and E3, who will be paid by the corresponding main contractor for the assigned activity. 
The methods of interim payment, stage payment, and advanced payment are used in this example for each company. The system retrieves the relevant data for each company from the database of the project and calculates its own cash flow considering the defined payment mechanisms. The scenario of considering the costs of off-site materials is shown in Table 2. The system output for this scenario is shown in Figure 5 and 6 . The maximum negative cash flow and the date at which it will occur are calculated. The net area of the cash flow, which is the area under the cash flow diagram, is also calculated. The system has the ability to implement what-if analysis by changing any data elements and finding out the effect on the output. Changes can be made for the cost/duration of any process in the project and also for any payment conditions such as payment delay, payment retention, and the amount of advanced payment. The system will act as an aid to design or "fine-tune" payment mechanisms to individual projects characteristics and each member of the project team can compare different payment methods and select the most appropriate one.

\section{CONCLUSIONS}

The performance of integrated teams in managing construction projects can be enhanced if a fair payment mechanism is adopted. Appropriate payment is considered among the satisfactory factors for any project member. A considerable number of disputes in construction are linked to problems in payment, hence building an integrated cash flow for the project team would assist in less disputatious industry. Therefore, a methodology for testing different payment mechanisms to improve the effectiveness of project management has been presented in this paper. This methodology and the developed system to automate its usage can help projects' stakeholders and supply chain to forecast and plan their cash flow patterns in different payment mechanisms. The developed system has an advantage over the existing cash flow models where the focus has been limited to main contractors only. The system has the facility of comparing alternative payment mechanisms and helps selecting the most appropriate payment one. This will help in solving the problematic issues of cash management such as reducing bankruptcies, optimising cash flow by gaining fair payment on time, payment for off-site materials and enhancing the quality of the project process.

\begin{tabular}{|c|c|c|c|c|c|c|}
\hline \multirow[t]{2}{*}{$\mathrm{Nr}$} & \multirow[t]{2}{*}{ Activity Name } & \multirow[t]{2}{*}{ Dependency } & \multirow[t]{2}{*}{ Durations } & \multirow[t]{2}{*}{ Values $(£)$} & \multicolumn{2}{|c|}{ Contractors } \\
\hline & & & & & Main & Sub- \\
\hline 1 & Site set-up & - & 15 days & 18000.0 & A & - \\
\hline 2 & Foundations & 1 & 20 days & 27950.0 & A & A1 \\
\hline 3 & Drainage & 2 & 5 days & 6070.0 & A & $\mathrm{A} 1$ \\
\hline 4 & Ground floor & 2 & 25 days ${ }^{*} A$ & 30360.0 & A & A1 \\
\hline 5 & Frame & 2 & 100 days ${ }^{*} B$ & 162900.0 & B & - \\
\hline 6 & External walls ground & 5 & 20 days & 40105.0 & C & $\mathrm{C} 1$ \\
\hline 7 & External walls $1^{\text {st }}$ & 6 & 20 days & 40087.5 & C & C1 \\
\hline 8 & External walls $2^{\text {nd }}$ & 6 & 20 days & 40087.5 & C & C1 \\
\hline 9 & Internal walls ground & 6 & 35 days & 70087.5 & C & C1 \\
\hline 10 & Internal walls $1^{\text {st }}$ & 9 & 17 days ${ }^{*} \mathrm{C}$ & 34087.5 & C & C1 \\
\hline 11 & Internal walls $2^{\text {nd }}$ & 9 & 17 days ${ }^{*} \mathrm{C}$ & 34087.5 & C & $\mathrm{C} 1$ \\
\hline 12 & Internal doors & 9 & 10 days & 12000.0 & D & - \\
\hline 13 & Lift / stairs & 14 & 15 days & 20480.0 & D & - \\
\hline 14 & Roof & 5 & 50 days ${ }^{*} B$ & 80900.0 & B & - \\
\hline 15 & Watertight(milestone) & 12 & 10 days & 4140.0 & $E$ & $\mathrm{E} 1$ \\
\hline 16 & Windows \& Ext. doors & 11 & 10 days ${ }^{*} D$ & 28500.0 & $\bar{D}$ & - \\
\hline 17 & Plumbing \& Sanitary-ware & 11 & 15 days ${ }^{*} E$ & 10420.0 & $\mathrm{E}$ & E1 \\
\hline 18 & Mechanical Services & 11 & 15 days & 16000.0 & E & E2 \\
\hline 19 & Electrical Services & 11 & 15 days* $E$ & 7000.0 & $E$ & E3 \\
\hline 20 & Floor finishes & 16 & 12 days & 10300.0 & D & - \\
\hline 21 & Ceiling finishes & 11 & 20 days & 16700.0 & D & - \\
\hline 22 & Wall finishes & 20 & 22 days ${ }^{*} D$ & 17950.0 & D & - \\
\hline 23 & Fixtures \& fittings & 20 & 20 days & 18100.0 & D & - \\
\hline 24 & External works & 2 & 15 days & 12350.0 & D & - \\
\hline 25 & Handover \& clean & 24 & 7 days ${ }^{\star} \mathrm{D}$ & 5600.0 & D & - \\
\hline
\end{tabular}

Table 1: Data of the Example Project 
$\%$ of the off-site activities (Materials ordered) costs to the total costs $(Y)$ :

30

1) \% of the material costs to the total costs of materials $\left(X_{1}\right)$ :

20

Corresponding time lag $\left(T_{1}\right)$ :

1 month

2) \% of the material costs to the total costs of materials $\left(X_{2}\right)$ :

30

Corresponding time lag $\left(T_{2}\right)$ :

3) \% of the material costs to the total costs of materials $\left(X_{3}\right)$ :

50

Corresponding time lag $\left(\mathrm{T}_{3}\right)$ :

3 months

$\%$ of the payment considered to the material costs $(Z)$ :

$\mathrm{Z}=0$ (no consideration)

$Z=100$ (fully considered)

Table 2: Costs/payments for off-site activities

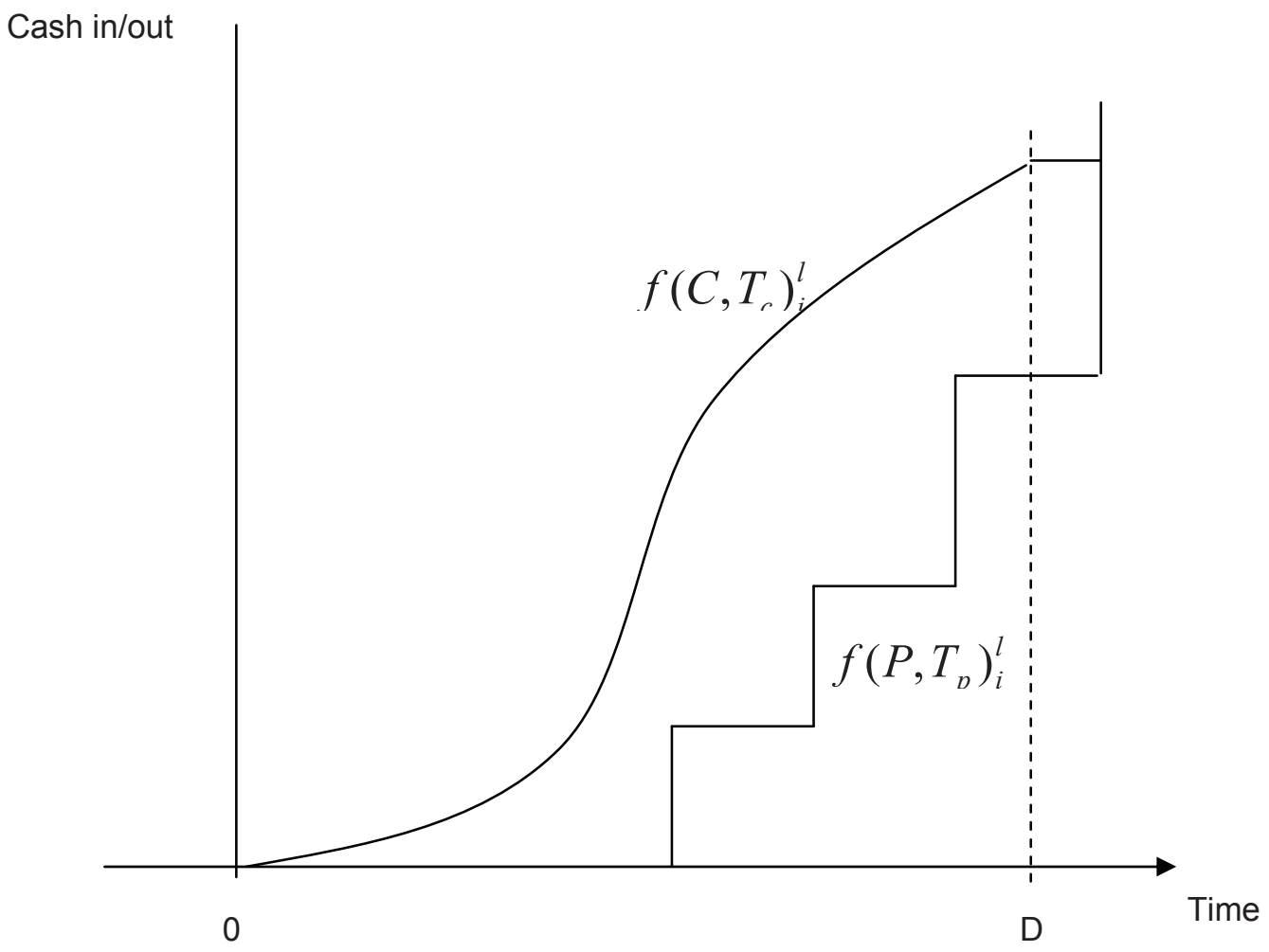

Figure 2. Project cash flow 


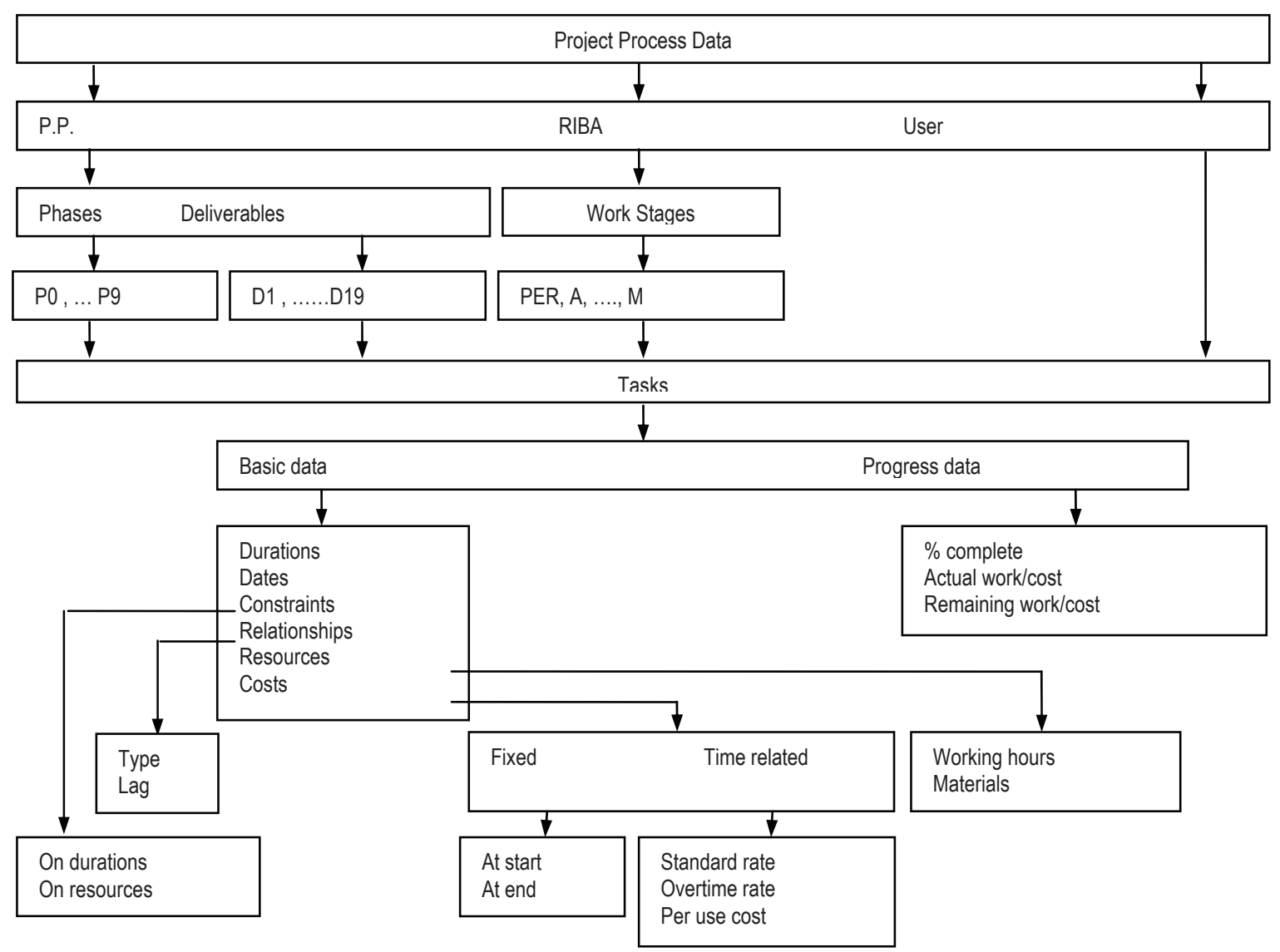

Figure 3. Planning and control data

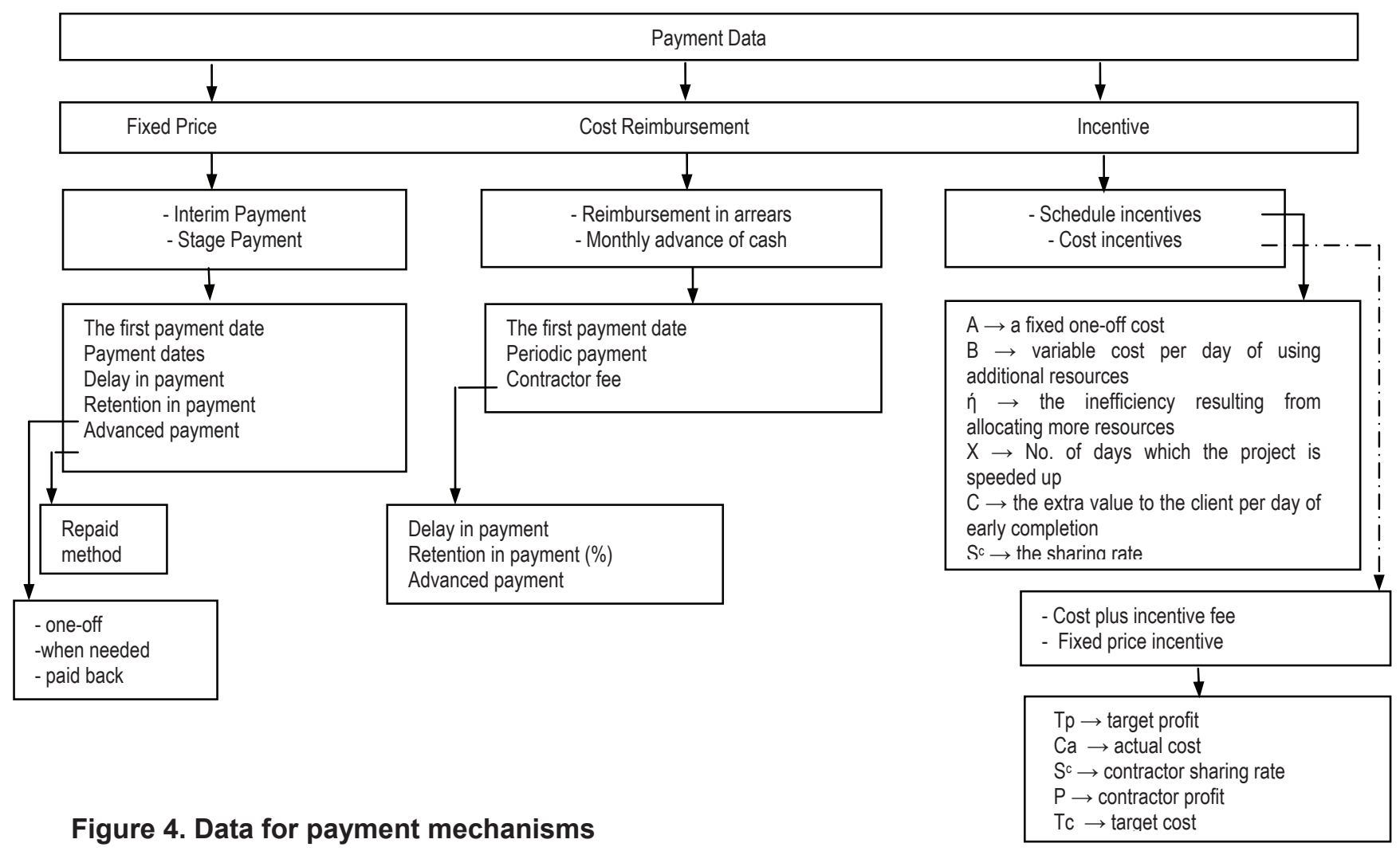




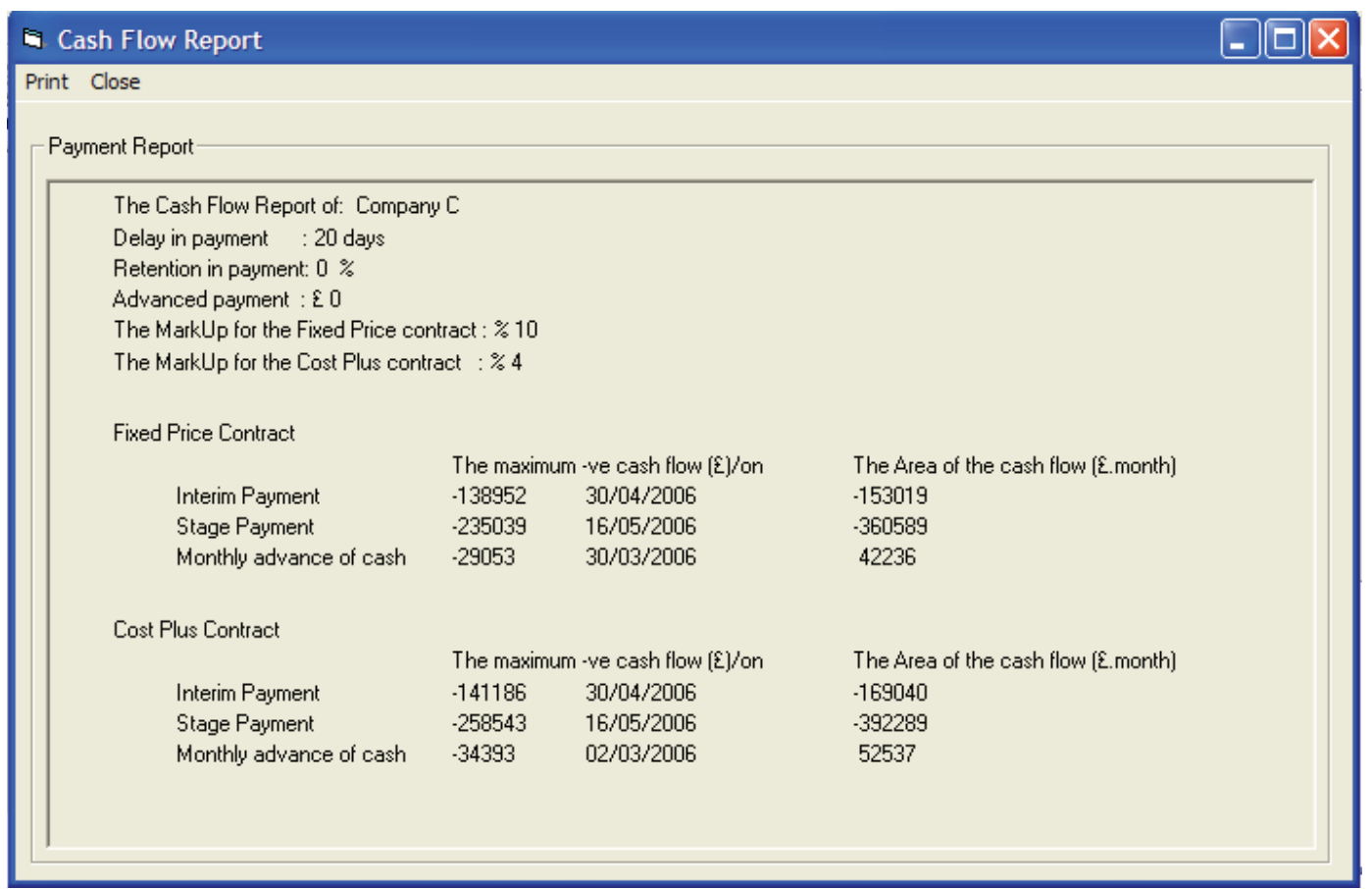

Figure 5. System output (reports on different payment methods for company C)

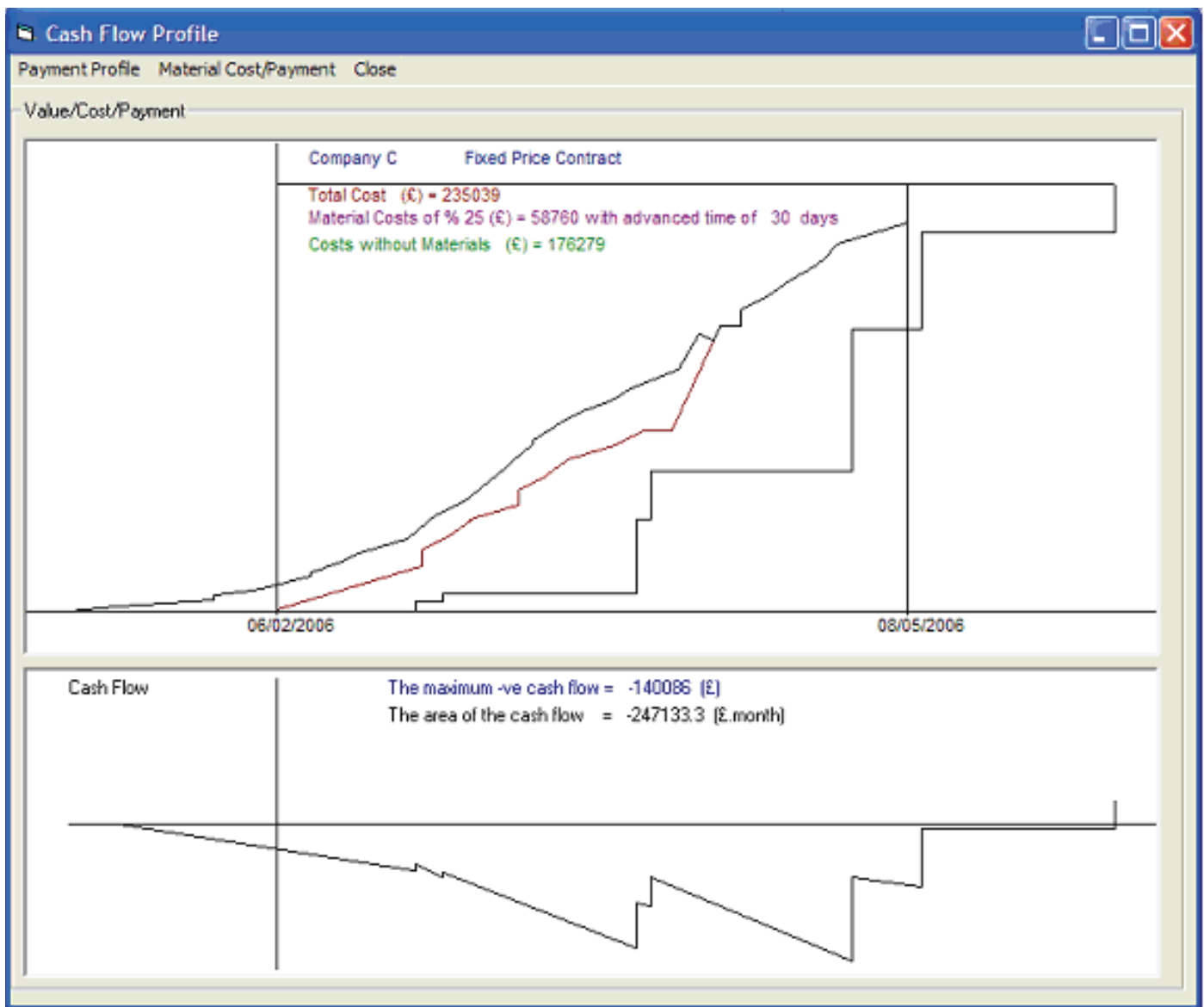

Figure 6. System output (cash flow patterns for company C considering off-site Material costs) 


\section{REFERENCES}

Abeysekera V., (2002). Re-engineering payment procedures: an agenda for client financed construction. In: Ng, S.T., Cheung, S., Lam, K. \& Poon, S. (eds.) Re-engineering construction: Enabling and motivating excellence, Hong Kong, 79-85.

Arditi D. \& Yasamis F., (1998). Incentive/disincentive contracts: perceptions of owners and contractors. Journal of Construction Engineering and Management, 124(5), 361-71.

Bubshait A.A., (2003). Incentive/disincentive contracts and its effects on industrial projects. International Journal of Project Management, 21(1), 63-70.

Cheetham D.W., Lewis J. \& Jones S.T., (1995). The effect of stage payments on contractors' cash flow - some possible consequences. Proceedings of CIB W96 - Architectural Management - Dublin.

Clough R.H. and Sears G.A., (1994). Construction contracting. sixth edition. New York: John Wiley \& Sons, Inc.

Egan Sir J., (1998). Rethinking Construction. London: Department of the Environment, Transport and the Regions.

IChemE., (2003). Form of contract: target cost contracts - the burgundy book, first edition. Rugby: IChemE.

IChemE., (2002). Form of contract: reimbursable contracts - the green book, third edition. Rugby: IChemE.

Kagioglou M., Cooper R., Aouad G., Hinks J., Sexton M. \& Sheath D.M., (1998). A generic guide to the design and construction Process Protocol. University of Salford, ISBN 0902896-17-2.

Latham Sir M., (1994). Constructing the team: Final report of the government/industry review of procurement and contractual arrangements in the UK construction industry. London: HMSO.

Masterman J.W.E., (2002). An introduction to building procurement systems, second edition. London: Spon Press.

Motawa I. and Kaka A., (2006). The architecture of an IT system for payment methods in construction. Proceedings of the Fifth International Conference on Engineering Computational Technology, Las Palmas de
Gran Canaria, Spain, 12-15 September 2006, paper 143.

O'Reilly M.P., (1993). Principles of construction law. Essex: Longman Group UK Ltd.

Potts K.P., (1988). An alternative payment system for major 'fast track' construction projects. J. of Construction Management and Economics, Vol. 6, 25-33.

Potts K., (1995). Major construction works: contractual and financial management. Harlow: Longman Group Limited.

RIBA Publications (2001). Architect's handbook of practice management, $7^{\text {th }}$ edition. London: RIBA Publications.

Smith N.J. (ed.), (2002). Engineering project management - second edition. Ames, IA: Blackwell Science.

Williams K., (1992). Civil engineering contracts - volume 1: the law, administration, safety. West Sussex: Ellis Horwood Limited. 